
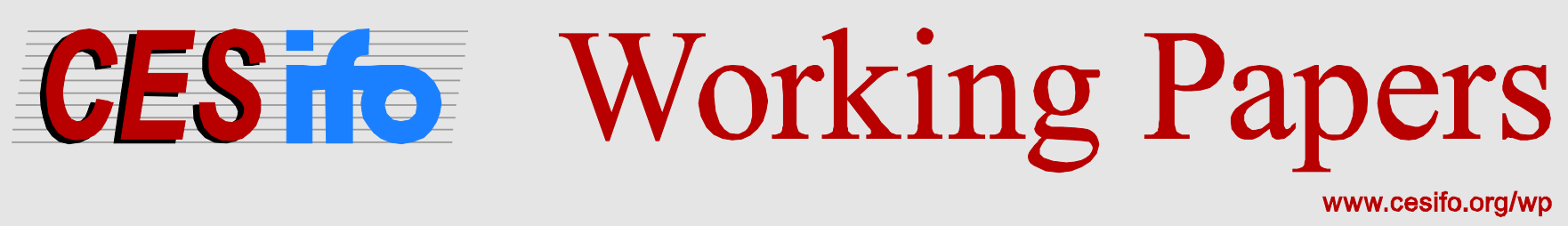

\title{
Strategic Housing Policy, Migration and Sorting around Population Thresholds
}

\author{
Kristof De Witte \\ Benny Geys
}

CESIFO WORKING PAPER NO. 5639

CATEGORY 1: PuBliC FinANCE

DECEMBER 2015

An electronic version of the paper may be downloaded

- from the SSRN website:

- from the RePEc website:

- from the CESifo website:

WwW.SSRN.com

Www.RePEc.org

www.CESifo-group.org/wp 


\title{
Strategic Housing Policy, Migration and Sorting around Population Thresholds
}

\begin{abstract}
We analyse whether, when and how local office-holders respond to the personal, economic incentives embedded in exogenously imposed population thresholds leading to an increased number and/or remuneration of local office-holders. Using data from all 589 Belgian municipalities over the period 1977-2014, local politicians are found to purposefully influence population growth through policy measures aimed at stimulating net in-migration when approaching important population thresholds. We provide evidence that strategic housing policy decisions - i.e. granting additional building permits early in the election cycle to maximize population growth just before the 'deadline' to surpass a population threshold - act as a key mechanism.
\end{abstract}

JEL-Codes: H700, J180, R230, R380.

Keywords: rent-seeking, political agency, regression discontinuity designs, building permits.

Kristof De Witte

Leuven Economics of Education Research

University of Leuven (KU Leuven)

Naamsestraat 69

Belgium - 3000 Leuven

kristof.dewitte@kuleuven.be
Benny Geys

Norwegian Business School (BI)

Nydalsveien 37

Norway - 0442 Oslo

Benny.Geys@bi.no

Benny Geys is grateful to FWO Vlaanderen (grant nr. G.0022.12) for financial support. We would like to thank Jon Fiva, Ronny Freier, Wim Moesen and Rune Sørensen for valuable comments and discussions. 


\section{Introduction}

In many countries, the number of local government officials (i.e. councillors and alderman) as well as their remuneration increase in stages at arbitrary population thresholds. Since these thresholds are typically institutionalised in a legal framework set by a higher-level government and not chosen by local governments themselves, they are arguably exogenous to local decision-making. Consequently, they offer - in ideal circumstances - an interesting environment to compare social, political and economic outcomes in jurisdictions just above and below population thresholds determining a change in local political institutions (such as government size, mayor/alderman remuneration, or the municipal electoral system). In other words, they can help sidestep crucial endogeneity concerns, which arise because "political units that adopt different policies typically differ not just in the policy of interest but also in other ways that may be difficult to control for in a regression" (Eggers et al., 2015: 1). Unsurprisingly, therefore, recent years have witnessed a proliferation of work exploiting this approach to assess the causal effects of specific public policies. ${ }^{1}$

Yet, as already argued by Imbens and Lemieux (2008), McCrary (2008) and Urquiola and Verhoogen (2009), one critical assumption underlying the validity of RD designs is the absence of strategic sorting around the exploited threshold(s). This can represent a very strong assumption. For instance, when the treatment assignment is known (e.g., because it is prescribed by law), agents might be able to manipulate or influence the running variable (such as population figures) in order to locate themselves on the desired side of the threshold(s). Furthermore, politicians could have a strong personal, economic incentive to engage in strategic behaviour when surpassing a given population threshold implies higher remuneration or a larger government size (in which case more politicians might qualify to receive remuneration). To the extent that such manipulation can be achieved with a reasonable degree of accuracy, it will translate into observable levels of sorting around the imposed cut-off(s). Substantial evidence of such sorting has been found in Brazil (Litschig, 2012), but not in Sweden (Hinnerich-Tyrefors and Pettersson-Lidbom, 2014). In a recent

\footnotetext{
${ }^{1}$ Recent examples include studies using data from, for instance, Brazil (Fujiwara, 2011; Litschig, 2012; Brollo et al., 2013), France (Eggers, 2015), Germany (Egger and Koethenbuerger, 2010; Arnold and Freier, 2015), Italy (Gagliarducci and Nannicini, 2013; Bordignon et al., 2013), Morocco (Pellicer and Wegner, 2013), the Netherlands (van der Linde et al., 2014), Sweden (Pettersson-Lidbom, 2012; Hinnerich-Tyrefors and Pettersson-Lidbom, 2014) and the United States (Hopkins, 2011).
} 
comparative analysis, Eggers et al. (2015) uncover very strong evidence of sorting behaviour in France and, especially, Italy. In Germany, statistically significant sorting is found only around a more limited number of particularly important thresholds (i.e. those leading to higher mayor/alderman remuneration and a larger local council size).

While sorting thus appears a realistic concern, the potential mechanisms behind it have received little attention thus far. Clearly, outright manipulation of population figures is one possibility (Litschig, 2012; Foremny et al., 2015). However, population figures in many developed countries are recorded, collected and/or verified by a central agency, which may leave less occasion for outright manipulation. Even so, politicians might still be able to influence population developments through specific public policies. One can thereby think of, for instance, urbanization plans, baby bonus schemes, tax rebates for making a municipality one's official residence, and so on. Clearly, such policies are less likely to precisely determine municipalities' position immediately around the threshold, but might have a non-negligible impact on local population growth rates - and thereby influence municipalities' overall position relative to the threshold.

The presence and empirical relevance of such policy-based sorting mechanisms is important for the validity of RD designs for two reasons. First, they can undermine the value of density-based tests of sorting such as the McCrary (2008) test, which rely on the existence of a structural break in the frequency distribution $a t$ the threshold. When public policies do not allow fine-tuning one's population count, the break in the frequency distribution at the threshold is likely to be fuzzy at best. Second, and more optimistically, understanding how municipalities try to influence population developments around population thresholds provides an important possibility to directly control for such policy-based sorting mechanisms when performing RD analyses - and thereby increase the validity of the inferences drawn from them (Eggers et al., 2015: 19).

The main contribution of this paper lies in assessing how and when - in the absence of outright manipulation options - local governments can achieve influence over population figures, such as to locate themselves on the desired side of legally imposed population thresholds. Our empirical focus thereby predominantly concerns local housing policies. We argue that these represent a particularly appealing opportunity to bear on local population developments, since local 
governments often have far-reaching autonomy over spatial planning decisions on their territory. It is, for instance, usually the prerogative of the local government to grant or refuse building permits. As a result, local governments close to a population threshold might have an incentive to actively - and at low immediate financial cost to the municipality - influence population growth rates by stimulating net in-migration via strategic housing policy decisions. Furthermore, since the relevant population count is often recorded at specific points in time (e.g., 1 January of an election year), such strategic actions are most likely to arise just before such 'deadlines'.

Clearly, while having important methodological implications for studies exploiting population thresholds in RD designs, our analysis also directly contributes to the vast literature on political agency since it provides new (causal) evidence on rent-seeking behaviour in local administrations. Indeed, by investigating whether, when and how local office-holders strategically instigate public policies targeting the higher remuneration that arises from surpassing the exogenously imposed threshold, we can assess their response to personal, economic incentives. From this perspective, our article is closely related to, for instance, studies analysing similar threshold effects in the public administration literature on management-by-objectives (for a recent discussion, see Hood, 2006) and the education economics literature on the undesired side-effects of school accountability systems based on students' test scores (Reback, 2008; Neal and Whitmore Schanzenbach, 2010; Rockoff and Turner, 2010).

Using data from all 589 Belgian municipalities over the period 1977-2014, our main findings can be summarized as follows. First, we find very little evidence of sorting using traditionally employed density tests (McCrary, 2008). Yet, despite the absence of a clear structural break in the density at the threshold(s), we do observe a strong upward trend in the density around the threshold(s). This suggests that local administrations may not be able to fine-tune their position just right of the population threshold, but can - and ostensibly do - influence their general position on the right side of the threshold. Second, underlying this general sorting pattern, we show that municipalities close to a relevant population threshold record significantly higher population growth rates. This jump in the population growth rate is equivalent to approximately $11 \%$ of the average annual population growth rate across all municipalities. Third, the observed effects on population growth derive almost exclusively from significantly higher net in-migration, while no 
substantive effects are observed for birth and death rates. Fourth, and crucially, local housing policy decisions act as a key mechanism since municipalities close to a population threshold are found to approve significantly more building permits for residential housing (no similar effect materializes for non-residential buildings). This effect is concentrated in municipalities just below the population thresholds and is particularly strong for building permits for apartments, which arguably reflects that apartment buildings allow for faster population growth in the short term relative to one-family houses. Finally, we provide some evidence that municipalities close to a population threshold strategically time their housing policy decisions. Since 1 January of an election year acts as a 'deadline' for recording the relevant population count, they approve more permits for apartments early in the six-year election cycle. This accounts for the time-lag induced by the building process, and translates into effective population growth in years immediately prior to the relevant counting date. Our results are robust for placebo tests with different population thresholds and different lag structures on the variables of interest.

\section{Institutional framework and data}

\subsection{Population thresholds in Belgium}

Belgian municipalities are governed through a parliamentary system with a legislative branch (the local council) and executive branch (the local government). Municipal elections take place on the second Sunday of October under a fixed electoral cycle of six years, whereby eligible citizens cast their ballot to elect local councillors using a system of Proportional Representation. The composition of the local government (i.e. the College of Mayor and Alderman) is subsequently determined by the party or parties holding a majority position in the council. These parties decide upon, and formally appoint by majority vote, the mayor and alderman, which are exclusively selected among their councillors. There are no term limits for councillors, alderman nor the mayor.

Both the size of the council (ranging between 7 and 55 councillors) and the College (ranging between 2 and 10 alderman, plus the mayor) are directly determined by the municipality's number of inhabitants on 1 January of the most recent election year. As illustrated in the first two columns of table 1, there are 24 (8) population thresholds at which the size of the council (College) increases. Similarly, the remuneration of the mayor - which has been historically linked to the remuneration of national ministerial officials (between 1976 and 2000) and the municipal secretary 
(between 2001 and 2006), but is currently tied to the remuneration of national parliamentarians is a function of the number of inhabitants on 1 January of the most recent election year. ${ }^{2}$ Table 1 indicates the main population thresholds where the remuneration of the mayor (and therefore also the alderman) increases, and how the employed thresholds have developed over time. All these thresholds were originally set by the Belgian national government, but local officials' remuneration is since 1999 under the authority of the regional governments (i.e. Flanders, Brussels and Wallonia) as part of a further decentralisation of the Belgian political system. We return to the implication of these legal changes for our empirical analysis in more detail in section 3, but should stress that thus far the same population thresholds have always been applicable to all Belgian municipalities.

\section{TABLE 1 ABOUT HERE}

In table 1, 17 population thresholds are recorded in boldface. These are thresholds at which both the number of local councillors and the remuneration of local office-holders (i.e. mayor and alderman) increases at least during some years of our sample period. We focus on these thresholds in the ensuing analysis for three reasons. First, these are the most commonly exploited type of population thresholds in population-based RD designs, which heightens the relevance of analysing potential strategic behaviour around them. Second, the results in Eggers et al. (2015: 17) indicate that "the largest [sorting] effects are generally found when both council size and salary of the political personnel are changing at the same time". As such, these thresholds represent a best-case scenario to analyse the potential mechanisms underlying sorting behaviour by local governments. Finally, the pecuniary incentives of mayor and alderman at these thresholds are arguably aligned with the incentives of local political parties, since an increase in the number of councillors improves parties' probability to gain at least some seats (Rae, 1967; Sartori, 1968; Taagepera and Shugart, 1989). The reason is that a larger number of available seats increases the proportionality of the electoral system (Lijphart, 1999; Farrell, 2001). Hence, the motivation of all agents involved

\footnotetext{
${ }^{2}$ The wage of the alderman is linked to that of the mayor, and thus by construction increases at the same population thresholds as the mayoral wage. Local councillors do not receive a wage in Belgium, but are generally paid a fixed amount for every council meeting they attend. This attendance fee is determined by the local council subject to a simple majority vote, and is therefore not linked to specific population thresholds.
} 
in local politics to influence population figures is likely to be maximised at this subset of population thresholds.

It is important to observe at this point that the population figures employed for determining the size of the council and mayor/alderman remuneration are obtained from the national registry ('Rijksregister'). More specifically, population data are in practice collected by each municipality's registry office - which records births, deaths and moves at the local level. This information is then centralized in the Rijksregister, which is governed by the Belgian Ministry for Internal Affairs. The latter verifies the information provided by the municipalities, and also crossreferences it with the large-scale population surveys held approximately every ten years since 1846 (most recently in 2001). Risk of large-scale outright tampering with the resulting final population figures by Belgian municipalities thus appears unlikely.

\subsection{Data}

For each municipality in Belgium, we collected annual information from the National Institute for Statistics on their total population, year-on-year population growth, births, deaths, in- and outmigration, gender and age composition, average real per capita income (in 1000EUR, base year is 2000), and the absolute number of approved building permits (for apartments, one-family residences, non-residential buildings and renovations). This was complemented with information from the Federal Employment Office on the municipal unemployment rate. Our final dataset includes all 589 Belgian municipalities, and covers the period between the large-scale municipal amalgamation operation of 1976-77 and 2014. Summary statistics for all these variables are presented in Table A.1 in appendix A, which also indicates the actual availability over time for all variables.

Before turning to the main analysis, table 2 evaluates whether municipalities just below and above our main population thresholds are similar in terms of several socio-demographic characteristics (using a $2 \%$ window around the thresholds). The results from simple difference-in-means t-tests included in the last column of table 2 indicate some statistically significant differences between both groups in terms of the shares of elderly $(p<0.01)$ and unemployed $(p<0.10)$, although both differences remain substantively very small (less than a half percentage point). Similar results are 
obtained when replicating the analysis for narrower windows around the threshold, but widening the evaluation window tends to indicate increasingly relevant differences between both groups (details upon request). This suggests that a window size beyond $2 \%$ makes the inclusion of control variables for socio-demographic characteristics progressively more important to avoid biased inferences. We therefore include a full set of socio-demographic control variables throughout our analysis, and return to the choice of our evaluation window below.

\section{TABLE 2 ABOUT HERE}

\section{Empirical strategy}

Our estimation approach is based on the following baseline regression model (with subscripts $i$ and $t$ for municipalities and time, respectively):

$$
Y_{i t}=\alpha_{i}+\beta_{1} \text { Population Threshold }{ }_{i t}+\delta X_{i t}+\gamma_{t}+\varepsilon_{i t}
$$

In equation (1), $Y_{i t}$ represents a set of dependent variables reflecting either demographic developments (i.e. population growth, births, deaths and net in-migration) or housing policy parameters (i.e. the number of various types of building permits) in municipality $i$ at time $t$. Population growth is defined as the year-on-year change in the municipality's population size (in percent). Births and deaths are the number of births (deaths) as a share of the total population, while net in-migration is the difference between the number of immigrants and emigrants as a share of the total population. Housing policy is captured by the absolute number of building permits for, respectively, residential properties (either apartments or one-family residences), nonresidential properties, or renovations of residential buildings. We consider the absolute number as this is reflects the number of subsequent constructions, which is what matters for reaching the next population threshold.

The key independent variable - Population Threshold $i t$ - is an indicator variable equal to 1 for municipalities $i$ whose population size in year $t$ is within $2 \%$ of a population threshold associated 
with higher remuneration of mayors and alderman and larger council size (0 otherwise). ${ }^{3} \mathrm{We}$ thereby account for the exact time period any particular threshold has been legally valid, and take the year of the official publication of legal changes as indicative of the (latest possible) moment municipal leaders become aware of any changes in the applicable thresholds. While no changes have been implemented to the thresholds affecting the number of councillors and alderman since the municipal amalgamation in 1976-77, the population thresholds determining mayoral wages were changed by the law of 4 May 1999 and the decree of 15 July 2005 (see table 1). Hence, our operationalisation of Population Threshold $i t$ allows for the fact that local officials could already respond to the new thresholds from, respectively, 1999 and 2005 onwards.

We initially include municipalities above and below the relevant population thresholds in our operationalisation since municipalities cannot perfectly fine-tune population parameters, and thus might still witness the effects of policies stimulating population growth after having surpassed the threshold. This operationalization covers $8.0 \%$ of all municipality-years in the dataset. Nonetheless, we naturally also differentiate between municipalities just below $(4.2 \%$ of municipality-years) and just above (3.9\% of municipality-years) relevant population thresholds. We expect $\beta_{1}>0$ in the model with population growth as the dependent variable, which would imply that municipalities close to a population threshold strategically stimulate population growth. The remaining dependent variables then allow us to verify potential mechanisms behind this effect. On the one hand, the models analysing births, deaths and net in-migration allow differentiating natural population growth (through births and deaths) from population mobility. On the other hand, the models using housing policy parameters assess the extent to which municipalities strategically influence the approval of building permits, which can subsequently translate into changing population size. ${ }^{4}$

\footnotetext{
${ }^{3}$ As always, the chosen window size or bandwidth must balance the requirement to have a sufficient number of observations 'treated' with a particular policy (in this case, closeness to the population threshold) and adding variation that is not directly attributable to the policy (which becomes more likely when expanding the window size). We therefore experimented with five window sizes between $1 \%$ and $5 \%$ (with $1 \%$ increments). The main inferences from the analysis are very similar for windows between $2 \%$ and $4 \%$, and are statistically weakest when using a very narrow $1 \%$ window (due to insufficient observations very close to the relevant population thresholds). We report the results for the $2 \%$ window as it is the narrowest window with sufficient statistical power.

${ }^{4}$ Auxiliary regressions confirm that an increase in residential building permits induces faster population growth in subsequent years. This effect is strongest one or two years after the increase in residential building permits, and levels off afterwards. Interestingly, increases in non-residential building permits tend to have the opposite effect, and are associated with slower population growth in subsequent years (details upon request).
} 
$X_{i t}$ is a vector of control variables including population size, unemployment rate, income per capita, and the share of elderly (over age 65) and women. Population size is important because it represents the running variable underlying the treatment assignment, while the remaining control variables aim to account for observed minor imbalances in these characteristics between municipalities close to and further from a population threshold (see table 2). We also add fixed effects at municipality level $\left(\alpha_{i}\right)$ and year $\left(\gamma_{t}\right)$. The municipality fixed effects are crucial to control for location-specific heterogeneity, and effectively imply that we draw inferences from variation in municipality-specific developments before/after reaching a relevant population threshold. The year fixed effects are necessary to capture variation, which is constant across all municipalities in a given year. Finally, $\varepsilon_{i t}$ stands for an i.i.d. error term. ${ }^{5}$

\section{Results}

\subsection{Sorting}

As a first indirect test for the presence of strategic influencing (or manipulation) of population figures in the vicinity of population thresholds, we evaluate whether municipalities display sorting behaviour around our 17 main population thresholds. We thereby follow the approach proposed in Eggers et al. (2015), and calculate the difference between municipalities' population sizes and the closest relevant population threshold for all municipalities in all years. We then stored all municipality-years when a municipality's population size was within $\mathrm{x} \%$ of a threshold (with $\mathrm{x}=$ $1, \ldots, 5)$, and also experimented with absolute cut-offs at 100, 250 and 400 inhabitants around a threshold. None of these alternatives affected our results (details upon request). Figures 1 and 2 plot the results using a cut-off at 250 inhabitants (using a bin width of 5). Evidence of sorting would be reflected in a significant jump at the threshold (normalised to 0 in figures 1 and 2).

\section{FIGURES 1 AND 2 ABOUT HERE}

\footnotetext{
${ }^{5}$ As we observe the same municipalities over time and intra-Belgium migration induces some degree of dependence across municipalities' population sizes, one could argue that standard errors should be clustered at the municipality level. As we rely on municipality fixed effects estimations, we abstain from doing so here. Yet, it is important to note that all results reported below are robust to combining municipality fixed effects with clustered standard errors at the municipality level - even though significance levels tend to decline somewhat.
} 
Figure 1 does not appear to substantiate significant sorting in the immediate vicinity of important population thresholds in Belgian municipalities. As a formal assessment, we calculated the McCrary (2008) test statistic, which "estimates the density of the running variable (i.e. absolute distance in inhabitants to a population threshold) separately on the left and right of the threshold and tests for a jump or drop in the density at the threshold" (Eggers et al., 2015: 14). The result when using all available observations is depicted in figure 2. The test confirms an apparent lack of sorting at the threshold(s), since although the McCrary test statistic is positive, it remains relatively small and is not statistically significantly different from zero $(0.156 ; p>0.10)$. Similar insignificant results are also obtained when splitting the sample in small and large municipalities, independent of where we set the cut-off between both groups.

Nevertheless, estimating a third-degree fractional polynomial on the frequency distribution underlying figure 1 suggests a local maximum in the density at approximately +80 . A graphical representation of this analysis is provided by the solid line in figure 1. Although municipalities thus may not be able to situate themselves just right of the population threshold, they can - and ostensibly $d o$ - influence their general position on the right side of the threshold. Hence, the absence of sorting at the threshold in figure 1 is not a necessary, nor a sufficient, condition to reject strategic local-level policies aimed at stimulating desired population developments.

To explain this result, we should bear in mind that - unlike outright manipulation of population figures (Litschig, 2012; Foremny et al., 2015) - policy measures aimed at stimulating population growth cannot be expected to fine-tune municipalities' position immediately above the threshold. Moreover, there is likely to be general uncertainty regarding "the regular connections between [policy] instruments and outcomes" (Chapell and Keech, 1986: 71; see also Tufte, 1980; Bernanke and Mishkin, 1997; Wieland, 2000), as well as coordination problems when diverse policy actions are implemented at various levels of government or within different departments at the same level of government (see Franzese, 2002, for similar arguments concerning the difficulty of timing desirable socio-economic outcomes around elections). As a result, local office-holders may well be 'playing safe' to avoid the risk of just missing the threshold - which would require them to wait six years until the next population assessment (i.e. at the next local election). 


\subsection{Population developments around the threshold}

As mentioned, population growth can in principle be achieved through two means: natural growth (i.e. births and deaths) and net in-migration. As such, local governments have two 'tools' - with concomitant sets of conceivable policy measures - to try to locate themselves on the desired side of an important population threshold. The first includes stimulating the birth rate among its inhabitants (assuming that individuals' deaths are beyond the power of local governments), whereas the second consists of encouraging more people to move in rather than out of the municipality. In table 3, we look at these two fundamental channels by reporting the results from estimating equation (1) for four different dependent variables: year-on-year population growth rate ('Growth'), the number of births as a share of the total population ('Birth'), the number of deaths as a share of the total population ('Death'), and the difference between the number of immigrants and emigrants as a share of the total population ('Net migration').

\section{TABLE 3 ABOUT HERE}

The first column in table 3 illustrates that municipalities close to one of our 17 important population thresholds witness a population growth rate, which lies on average $0.055 \%$ higher than the population growth rate in municipalities further from the threshold. This is equivalent to $11 \%$ of the average annual population growth rate across Belgian municipalities (i.e. 0.513\%), which represents a substantively meaningful effect. The remaining three columns suggest that this faster population growth derives predominantly from a significantly higher level of net in-migration. The point estimate here equals $10 \%$ of the average annual net in-migration across Belgian municipalities (i.e. $0.386 \%$ ). Municipalities close to the population thresholds do not have significantly different birth rates compared to municipalities further from the threshold. This suggests that any local public policies aimed at stimulating births - such as a payment to parents at the birth of a child (which are common in Belgium) - are not implemented strategically to surpass legally imposed population thresholds. ${ }^{6}$ Finally, although column 3 suggests that the death

\footnotetext{
${ }^{6}$ We surveyed all 570 municipalities in the Flemish (Dutch-speaking) and Walloon (French-speaking) regions of Belgium about any payments they make to parents at the birth of a child. Such a policy exists in 364 of the 520 municipalities responding to our survey (i.e. 70\%). Still, the average payment remains small (i.e. usually less than 100EUR), most municipalities appear to have implemented this policy immediately after the municipal amalgamation operation in 1976-77, and we could find no instance where it appears to have been implemented when the municipality was close to an important population threshold. Many respondents also explicitly indicated that this
} 
rate is somewhat lower in municipalities close to important population thresholds, this finding is substantively small (equivalent to less than $1 \%$ of the average annual death rate across Belgian municipalities) and not robust to using different window sizes. Moreover, it may at least in part derive from the fact that migration increases the municipal population with individuals less likely to die in the short term. Hence, the denominator in the death rate increases with migration while the numerator is left unchanged, inducing a decline in the observed death rate for purely mathematical reasons. ${ }^{7}$

Table 3 includes municipalities above and below the population thresholds in the operationalisation of our key independent variable. As such, we estimate the average effect of being close to a threshold, rather than the effect of approaching a threshold from below. While this aims to account for the fact that precise targeting of policies inducing population growth is difficult, one might argue that any observed effects should be predominantly concentrated in municipalities just below a threshold. In table 4, we therefore provide separate results for municipalities close to but below the threshold (Panel I), and municipalities close to but above the threshold (panel II). ${ }^{8}$ Otherwise, the estimation model is equivalent to those presented in table 3. The most interesting message to be taken from table 4 is that the population growth rate is not significantly different just below and above a threshold. Municipalities above the threshold still tend to grow somewhat faster than municipalities further from a population threshold, which most likely reflects that policies aimed at stimulating population growth cannot be made ineffective immediately (we return to this below).

\section{TABLE 4 ABOUT HERE}

policy is considered a weak instrument to stimulate births (in part because the payment is too low to affect the choice of future parents), and is mainly viewed as part of a more general social policy to support families.

${ }^{7}$ All else equal, one can anticipate that a migration-driven increase in the population growth rate with $11 \%$ (see above) reduces the death rate with approximately the same amount. Given that the average death rate across Belgian municipalities lies just under $1 \%$, we would thus expect a decline of roughly $0.1 \%$ of the death rate for purely mathematical reasons - which is very close to the size of the effect observed in table 3 .

${ }^{8}$ Note that we always include all 589 Belgian municipalities in the estimations, and only change the operationalisation of our key explanatory variable between panels I and II. Alternatively, we could estimate equation (1) using only the observations when a municipality is close to a population threshold, and differentiate between municipalities above and below the threshold via an indicator variable for municipalities below the threshold. Although this approach drastically restricts the number of available observations, the sign and magnitude of the results remains consistent with those reported in the main text (full details upon request). 


\subsection{Housing policy as a mechanism to influence municipal population size}

Tables 3 and 4 raise a more detailed question on how municipalities foster population growth and net in-migration when approaching a population threshold. One plausible mechanism might lie in local housing policy since municipalities have considerable autonomy over spatial planning decisions. Municipalities close to, but below, an important population threshold might have an incentive to be less restrictive in granting building permits, or to stimulate the construction of additional residential housing via the allotment of new settlement areas. Exploring this potential mechanism, table 5 turns to an analysis of building permits for residential buildings (column 1), apartment buildings (column 2), one-family residences (column 3), non-residential buildings (column 4) and renovations of residential buildings (column 5). The estimation model is again given in equation (1), except that we lag our main explanatory variable with one year. The reason is that it usually takes at least one year to validate the building permit, construct the building and occupy the new accommodation (see also note 4). Table 5 again separates municipalities close to but below the threshold (Panel I) from municipalities close to but above the threshold (panel II).

\section{TABLE 5 ABOUT HERE}

Table 5 illustrates that the number of approved building permits for residential buildings significantly increases for municipalities approaching the population threshold from below (panel I), but that a similar observation fails to materialise for municipalities just surpassing the threshold (panel II). This difference between both panels is particularly interesting since local governments have direct control over housing policy decisions, and can thus more accurately target the approval of building permits to their perceived need (in terms of surpassing the population threshold). The size of the coefficient estimate in column 1 suggests that, on average, eight additional building permits are approved when a municipality's population size is nearing an important threshold, which is equivalent to $10 \%$ of the average annual number of building permits. Interestingly, no significant effect is found with respect to building permits for non-residential buildings (column 4). Furthermore, columns 2 and 3 highlight that the effect on residential buildings is exclusively concentrated in building permits for apartments. The nine additional building permits for apartments reflect $23 \%$ of the average annual number of building permits for apartments (or $11 \%$ 
of its standard deviation). There is no significant effect of the population threshold on building permits for one-family residences. This apparent focus on building permits for apartments rather than one-family residences makes intuitive sense. Indeed, if the goal is to reach and surpass the population threshold as quickly as possible, one-family residences are less 'efficient' compared to new apartments since they consume more open space (which is becoming a scarce commodity in many Belgian municipalities) and take longer to construct for a given 'return' in terms of additional residents. Finally, we observe that local administrations below and above the threshold grant more renovation permits. This is intuitive as new inhabitants of a municipality often renovate an existing house or apartment. Sufficient leeway in renovation permits might therefore trigger net migration. Overall, table 5 strongly suggests that local governments nearing a population threshold specifically target their housing policy towards housing options that promise the largest possible population growth in the short term.

\subsection{Elections and policy timing}

Given that the population thresholds expressly refer to the municipality's number of inhabitants on 1 January of the election year (see section 2.1), local governments arguably have a particularly large incentive to focus on this date to surpass the threshold. For example, if the threshold is surpassed during or after an election year, there is no effect on mayor/alderman remuneration nor a larger council size. In contrast, surpassing the threshold just before an election year is more advantageous since it would immediately lead to higher mayor/alderman remuneration and a larger council size. Moreover, surpassing the threshold well before the election year need not imply that the municipality's population count is still on the right side of the threshold when it really matters (i.e. on 1 January of the election year). This line of argument implies that strategic housing policy decisions should be taken some years before the next election, such as to - hopefully - induce higher population growth in years immediately preceding the election year.

To assess the empirical prevalence of such temporal pattern, we extend equation (1) with a set of interaction effects between Population Threshold $i t$ and indicator variables for different years in the election cycle (Election). We specifically introduce interaction effects for the election year itself $(e=0)$ as well as one, two and three years prior to the election $(e=-1,-2,-3)$. The remaining two years $(e=-4,-5)$ of the six-year election cycle act as the reference category: 


$$
\begin{aligned}
Y_{i t}= & \alpha_{i}+\beta_{1} \text { Population Threshold }_{i t}+{\text { E } \text { Election }_{e} . \text { Population }_{\text {Threshold }}+}+ \\
& \delta X_{i t}+\gamma_{t}+\varepsilon_{i t}
\end{aligned}
$$

To retain sufficient municipalities close to a population threshold in the different years of the election cycle, we set Population Threshold $i t$ equal to 1 for municipalities within a $2 \%$ window above and below a relevant threshold. ${ }^{9}$ Note also that identification here derives from the fact that different municipalities approach a population threshold during different election years. Hence, even though all municipalities hold elections on the same day (which implies we cannot include Election $_{e}$ independently due to perfect collinearity with the year effects $\gamma_{\mathrm{t}}$ ), we can nonetheless differentiate between year and election effects in the analysis. For ease of interpretation, the results are graphically presented in figure 3 for the dependent variables with the strongest effects in the foregoing analysis (i.e. population growth, net in-migration and apartment building permits). The different panels in figure 3 provide the coefficient estimates across the election cycle with associated $95 \%$ confidence intervals (calculated using standard errors adjusted for the covariance between the interacted variables).

\section{FIGURE 3 ABOUT HERE}

Figure 3 highlights that - controlling for year and municipality fixed effects as well as sociodemographic characteristics - population growth and net in-migration in municipalities close to important population threshold(s) is highest in the year prior to an election year. While the restricted number of observations limits the statistical power of our analysis at this point, the preelection growth rush nonetheless approaches statistical significance at 95\% confidence. In the first half of the electoral cycle and in the election year itself (when additional population growth arguably no longer matters for mayor/alderman remuneration and council size), population growth and net in-migration are lowest. Interestingly, a somewhat different picture emerges in the bottom panel of figure 3, where we focus on apartment building permits. The number of approved building permits for apartments is found to be significantly higher in municipalities close to a population

\footnotetext{
${ }^{9}$ Unfortunately, focusing only on municipalities approaching the population threshold(s) from below is impossible due to the lack of sufficient observations in each year of the election cycle.
} 
threshold when the election - and thus the 'deadline' to surpass the population threshold - is still some way into the future. Yet, no significant effects exist when the election is imminent. This is, again, intuitive as it takes at least one or two years before an apartment permit is effectively translated into population growth (see also note 3). All in all, these findings therefore are in line with the idea that local governments take into account the time it takes for building permits to translate into residential housing and, in turn, increased population size.

\subsection{Placebo tests}

Finally, we report the results of two placebo tests. The first of these consists of repeating the analysis at placebo population thresholds where, to the best of our knowledge, no policy changes occur. In particular, we choose the midpoint between the currently valid population thresholds and the next threshold included in table 1, and then randomly add 167 to the result to make sure we do not accidentally include a real population threshold (for a similar approach, see Eggers et al., 2015). As such, we set 12 placebo thresholds at 1392, 2417, 3667, 4667, 5667, 17667, 22667, 27667, 37667, 55167, 85167 and $175167 .{ }^{10}$ The results are presented in table X.1 of the online appendix. We thereby again focus on municipalities whose population is within a $2 \%$ window of the placebo threshold, and operationalize our central independent variable as 1 for municipalities approaching the population threshold from below (0 otherwise). All coefficient estimates in this exercise are small and remain statistically insignificant at conventional levels. Overall, therefore, these results confirm that our main results do not materialize at arbitrary population thresholds, but appear specific to the thresholds actually used in Belgium to increase mayor/alderman remuneration and the council size.

The second placebo test specifically concerns the results in table 5, which were obtained by looking at a one-year lag in our central explanatory variable. Naturally, similar results should not arise when instead introducing a one-year forward lag of our central explanatory variable, since there is no longer any incentive for strategic housing policy decisions after a municipality has passed the population threshold. This is borne out by the empirical analysis in table X.2 in the online appendix. Four out of five coefficient estimates in these placebo results are negative, and two of

\footnotetext{
${ }^{10}$ Equivalent results are obtained when we instead choose the midpoint between the current population thresholds and the previous threshold included in table 1, and then randomly subtract 167 from the result (details upon request).
} 
them are statistically significant at the $90 \%$ confidence level. These results are in the opposite direction to those in our main analysis. Moreover, such negative effects also weakly hint at a possible compensation effect whereby local governments that approved substantially more permits when approaching a population threshold reduce the number of approved permits once the threshold is surpassed.

\section{Concluding discussion}

This article evaluated whether, when and how - in the absence of outright manipulation options (Litschig, 2012; Foremny et al., 2015) - local governments try to achieve influence over population figures, such as to locate themselves on the desired side of legally imposed population thresholds leading increases in the number and/or remuneration of local office-holders. Our main findings suggest significantly faster population growth in municipalities close to important population thresholds, which is driven largely by significantly higher net in-migration. We furthermore provide evidence that local governments appear to strategically employ their housing policy to attract more inhabitants. Especially the number of approved building permits for residential apartments witnesses a significant increase when municipalities approach a relevant population threshold, compared to no significant changes in the number of permits for one-family houses and non-residential buildings.

We also observe a highly suggestive pattern with respect to the timing of policy actions. As 1 January of an election year serves as a formal 'deadline' with respect to the population threshold - and thus for setting the corresponding mayor/alderman remuneration and the size of the council - municipalities focus on this date. That is, municipalities start granting additional apartment building permits at the onset of their legislative term, which translates into higher population growth and net in-migration in the years immediately prior to the relevant election deadline. This temporal pattern is in line with the notion that strategic housing policy decisions act as a key mechanism for influencing the population growth rate when municipalities approach a population threshold with personal, economic implications for local office-holders. ${ }^{11}$

\footnotetext{
${ }^{11}$ Clearly, our analysis predominantly concentrated on building permits as a mechanism behind local governments' sorting behavior. Further research should examine whether other, potentially more subtle, alternative mechanisms are also employed - such as strategically timing the opening day-care facilities (to increase the municipality's
} 
These results first of all provide new evidence on rent-seeking behaviour in local administrations. Local office-holders' deliberate and strategic instigation of public policies targeting the higher remuneration for themselves when surpassing exogenously imposed population thresholds indeed strongly suggests that political agents respond to incentives related to personal, economic gain. Importantly, the exogenous nature of the imposed thresholds and our pre/post comparison of population and policy developments within the same municipality imply that our inferences are very likely to be causal in nature. As such, we contribute to a vast political economics literature on political agency and (self-)selection (Besley 2005, 2006; Gagliarducci and Nannicini, 2013; Geys and Mause, 2015). More broadly, however, our article also confirms that threshold-based public policies can have important unintended side-effects by distorting individuals' incentives. Similar threshold effects have indeed likewise been observed in the public administration literature on management-by-objectives (for a recent discussion, see Hood, 2006) and the education economics literature on test-based school accountability systems (Reback, 2008; Neal and Whitmore Schanzenbach, 2010; Rockoff and Turner, 2010).

Furthermore, our results have important potential implications for the internal validity of population-based RD designs, which requires that these thresholds are fully exogenous to the local administrations (Imbens and Lemieux, 2008; McCrary, 2008; Urquiola and Verhoogen, 2009; Eggers et al., 2015). If local jurisdictions influence their position around the threshold(s) through sorting behaviour, inferences drawn from such analyses cannot necessarily be interpreted as causal. The reason is that sorting makes observations on both sides of the threshold unequal in expectations. That is, while the thresholds themselves might be set exogenously and arbitrarily, the jurisdiction at both sides of the threshold might still have different unobserved characteristics (e.g. because the incentives and pay-offs at both sides of population thresholds are different). Yet, more positively, our evaluation of policy-based sorting mechanisms also provides an opportunity to increase the validity of the inferences drawn from RD analyses by including direct controls for them.

attractiveness to young families), the construction of elderly care centers, or the acceptance of more non-native migrants. 
Finally, our results can have important policy implications, since it might imply that local administrations become less restrictive in granting building permits when important population thresholds are nearby. Consequently, from a policy perspective, a mechanism of control or accountability by higher-level governments might be required to prevent the acceptance of lower standards when population thresholds come in reach. Moreover, since local office-holders' incentives for influencing population developments change over the electoral cycle, more accountability appears needed particularly at the onset of the legislative term in which a relevant population threshold is within reach. Overall, central administrations should be aware of the (perverse) incentives created by setting legally enshrined population thresholds. While such thresholds are often considered as a fair mechanism to distribute power and money, they can have unintended consequences when they induce sorting on the desired side of the threshold. 


\section{References}

Arnold, F. and R. Freier (2015). Signature Requirements and Citizen Initiatives: QuasiExperimental Evidence from Germany. Public Choice 162(1): 43-56.

Bernanke, B.S. and F.S. Mishkin (1997). Inflation Targeting: A New Framework for Monetary Policy? Journal of Economic Perspectives 11(2): 97-116.

Besley, T. (2005). Political Selection. Journal of Economic Perspectives, 19(3), 43-60.

Besley, T. (2006). Principled Agents? The Political Economy of Good Government. Oxford: Oxford University Press.

Bordignon, M., T. Nannicini and G. Tabellini (2013). Moderating Political Extremism: Single Round vs. Runoff Elections under Plurality Rule. IZA Discussion Papers No 7561.

Brollo, F., T. Nannicini, R. Perotti and G. Tabellini (2013). The Political Resource Curse. American Economic Review 103(5): 1759-1796.

Chappell, H.W. and W.R. Keech (1986). Party Differences in Macroeconomic Policies and Outcomes. American Economic Review 76(2): 71-74.

Egger, P. and M. Koethenbuerger (2010). Government Spending and Legislative Organization: Quasi-Experimental Evidence from Germany. American Economic Journal: Applied Economics 2(4): 200-212.

Eggers, A. (2015). Proportionality and Turnout: Evidence from French Municipalities. Comparative Political Studies 48(2): 135-167.

Eggers, A., R. Freier, V. Grembi and T. Nannicini (2015). Regression Discontinuity Designs Based on Population Thresholds: Pitfalls and Solutions. Mimeo.

Farrell, D.M. (2001). Electoral Systems: A Comparative Introduction. New York: Palgrave.

Foremny, D., J. Jofre-Monseny and A. Solé-Ollé (2015). 'Hold that Ghost': Using Notches to Identify Manipulation of Population-Based Grants. CESifo Working Papers 5578, pp. 40.

Franzese. R.J.Jr. (2002). Electoral and Partisan Cycles in Economic Policies and Outcomes. Annual Review of Political Science 5(1): 369-421.

Fujiwara, T. (2011). A regression Discontinuity Test of Strategic Voting and Duverger's Law. Quarterly Journal of Political Science 6(3-4): 197-233.

Gagliarducci, S. and T. Nannicini (2013). Do Better Paid Politicians Perform Better? Disentangling Incentives from Selection. Journal of the European Economic Association 11(2): 369-398.

Geys, B. and K. Mause (2015). The Limits of Electoral Control: Evidence from Final Term Politicians, Legislative Studies Quarterly forthcoming.

Hinnerich-Tyrefors, B. and P. Pettersson-Lidbom (2014). Democracy, Redistribution, and Political Participation: Evidence from Sweden 1919-1938. Econometrica 82(3): 961-993.

Hood, C. (2006). Gaming in Targetworld: The Targets Approach to Managing British Public Services. Public Administration Review 66: 515-521.

Hopkins, D.J. (2011). Translating into Votes: The Electoral Impact of Spanish-Language Ballots. American Journal of Political Science 55(4): 814-830.

Imbens, G.W. and T. Lemieux (2008). Regression Discontinuity Designs: A Guide to Practice. Journal of Econometrics 142(2): 615-635. 
Lijphart, A. (1999). Patterns of Democracy: Government Forms and Performance in 36 Countries. New Haven: Yale University Press.

Litschig, S. (2012). Are Rules-based Government Programs Shielded from Special-Interest Politics? Evidence from Revenue-Sharing Transfers in Brazil. Journal of Public Economics 96: 1047-1060.

McCrary, J. (2008). Manipulation of the Running Variable in the Regression Discontinuity Design: A Density Test. Journal of Econometrics 142(2): 698-714.

Neal, D. and D. Whitmore Schanzenbach (2010). Left Behind by Design: Proficiency Counts and Test-Based Accountability. Review of Economics and Statistics 92(2): 263-283.

Pellicer, M. and E. Wegner (2013). Electoral Rules and Clientelistic Parties: A Regression Discontinuity Approach. Quarterly Journal of Political Science 8(4): 339-371.

Pettersson-Lidbom, P. (2012). Does the Size of the Legislature Affect the Size of Government? Evidence from Two Natural Experiments. Journal of Public Economics 98(3-4): 269-278.

Rae, D.W. (1967). The Political Consequences of Electoral Laws (Revised Edition). New Haven: Yale University Press.

Reback, R. (2008). Teaching to the Rating: School Accountability and the Distribution of Student Achievement. Journal of Public Economics 92: 1394-1415.

Rockoff, J.E. and L.J. Turner (2010). Short Run Impacts of Accountability on School Quality. American Economic Journal: Economic Policy 2(4): 119-147.

Sartori, G. (1968). The Influence of Electoral Systems: Faulty Laws or Faulty Method? In Grofman B. and A. Lijphart (eds.), Electoral Laws and their Political Consequences, pp. 43-68. New York: Agathon Press Inc.

Taagepera, R. and W.F. Shugart (1989). Seats and Votes: the Effects and Determinants of Electoral Systems. New Haven: Yale University Press.

Tufte, E.R. (1980). Political Control of the Economy. Princeton: Princeton University Press.

Urquiola, M. and E. Verhoogen (2009). Class-Size Caps, Sorting, and the RegressionDiscontinuity Design. American Economic Review 99(1): 179-215.

Van der Linde, D., S. Falcke, I. Koetsier and B. Unger (2014). Do Wages Affect Politicians Performance? A Regression Discontinuity Approach for Dutch Municipalities. Tjalling $C$. Koopmans Research Institute Discussion Paper Series, nr. 14(15).

Wieland, V. (2000). Monetary Policy, Parameter Uncertainty and Optimal Learning. Journal of Monetary Economics 46(1): 199-228. 
Figure 1: Clustering around population thresholds

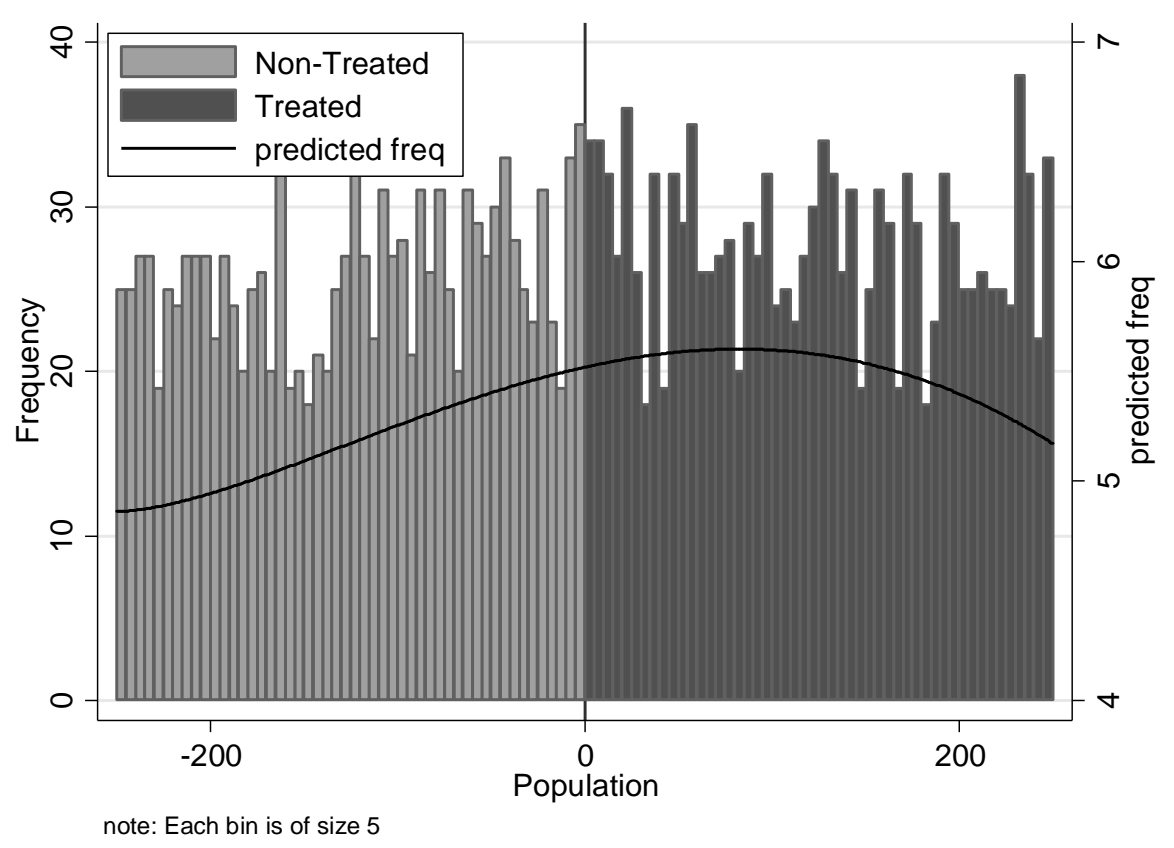

Note: The figure plots the distribution of municipalities' population sizes within a 250-person window around the 17 population thresholds associated with higher mayoral/alderman wages and larger council size. Each bin in the histogram is of size 5 (left-hand scale). The vertical axis designates the population threshold(s), with negative (positive) numbers indicating the number of inhabitants below (above) a population threshold. The line represents a fractional-polynomial prediction plot of the frequency distribution of municipalities around the population thresholds with a polynomial function of degree 3 (using a bin size of 1 in the underlying estimation, right-hand scale). 
Figure 2: McCrary test

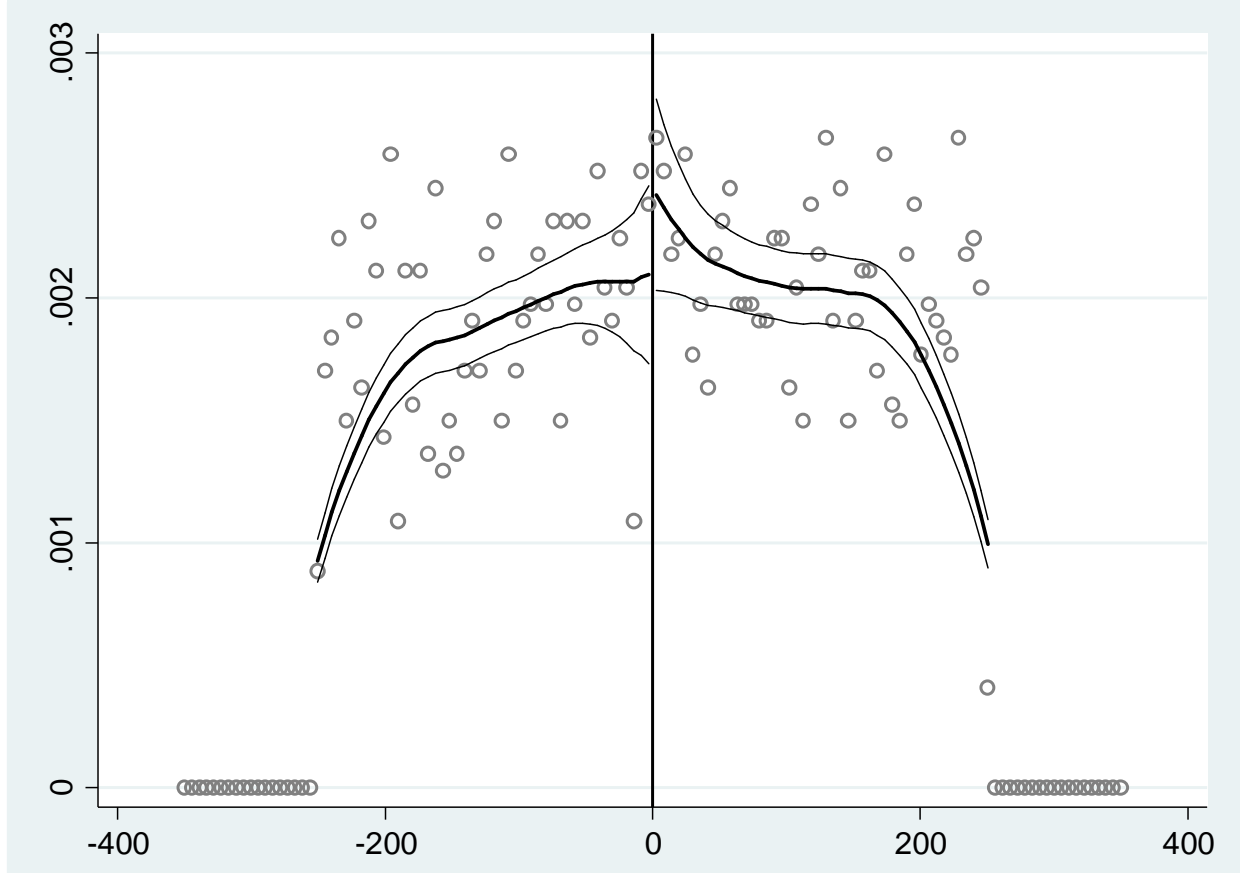

Note: The figure depicts the McCrary analysis for all cases pooled when looking at municipalities within a 250-person window around the 17 population thresholds associated with higher mayoral/alderman wages and larger council size. The zerodensity observations at the extremes of the graph are added by the DCdensity.ado to assist with smoothing. 
Figure 3: Growth, net in-migration and housing policy relative to elections

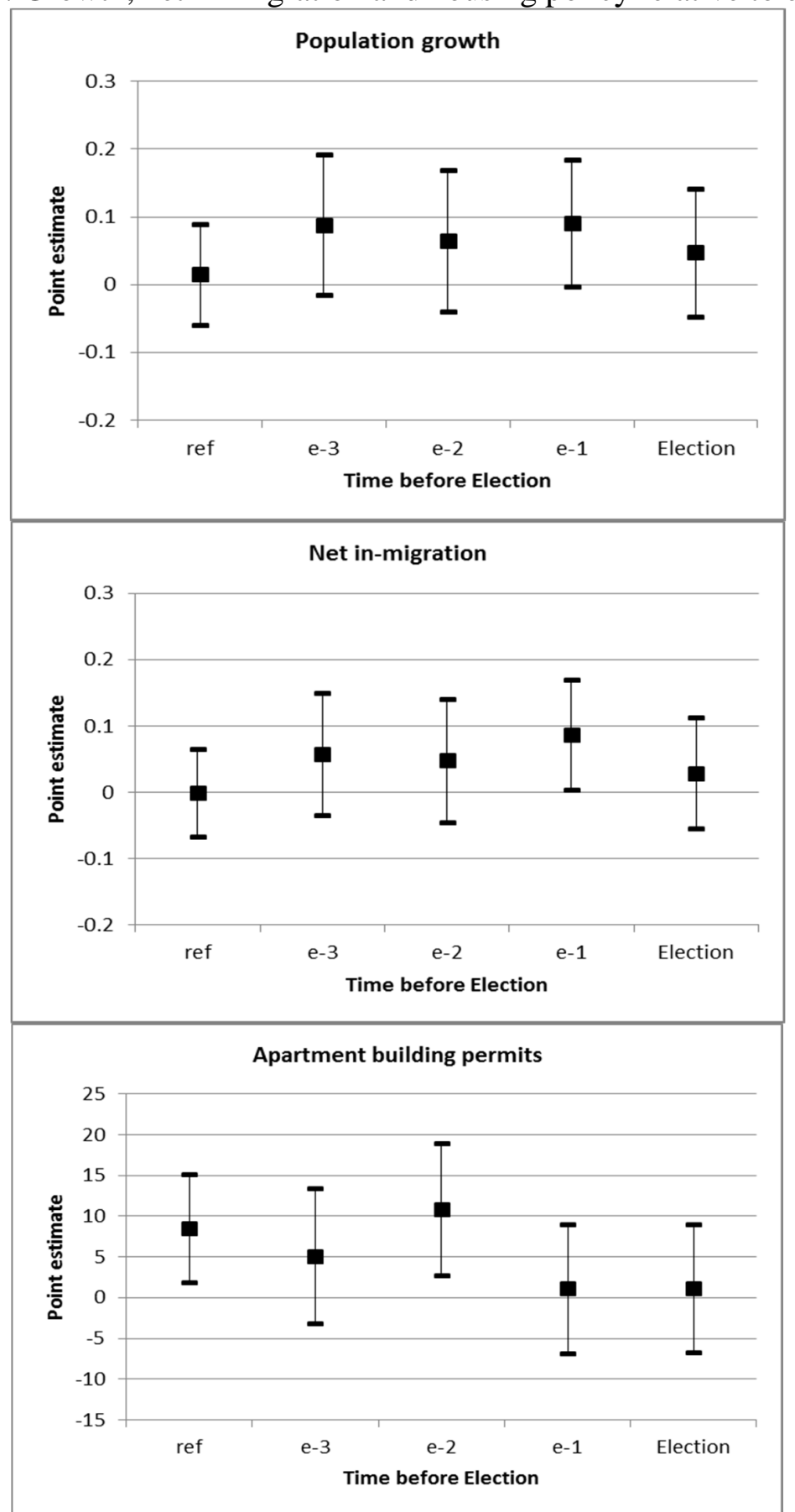

Note: The figure provides the coefficient estimates (with 95\% confidence intervals) of interaction effects between

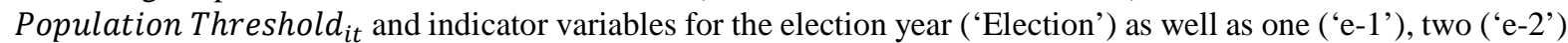
and three ('e-3') years prior to the election. The remaining two years of the six-year election cycle act as the reference category ('ref'). The dependent variables are the year-on-year population growth rate (top panel), the difference between the number of immigrants and emigrants as a share of the total population (middle panel), and the absolute number of building permits for apartment buildings (bottom panel). All models include controls for income, unemployment, age and gender distribution, as well as a full set of year and municipality fixed effects. 
Table 1: Important population thresholds for Belgian municipalities

\begin{tabular}{|c|c|c|c|c|c|}
\hline & $\begin{array}{l}\text { Number of } \\
\text { councillors }\end{array}$ & $\begin{array}{l}\text { Number of } \\
\text { alderman }\end{array}$ & $\begin{array}{l}\text { Mayor wage (as \% of } \\
\text { ministerial official) }\end{array}$ & $\begin{array}{l}\text { Mayor wage (as \% of } \\
\text { municipal secretary) }\end{array}$ & $\begin{array}{l}\text { Mayor wage (as \% of } \\
\text { national MP wage) }\end{array}$ \\
\hline Time period & 1977-now & 1977-now & $1977-2000$ & $2001-2006^{a}$ & since $2007^{b}$ \\
\hline less than 300 & 7 & 2 & $17.32 \%$ & $75 \%$ & $26 \%$ \\
\hline 301 & & & & & $29 \%$ \\
\hline 501 & & & & & $31 \%$ \\
\hline 751 & & & & & $35 \%$ \\
\hline 1000 & 9 & 3 & & & $39 \%$ \\
\hline 1251 & & & & & $40 \%$ \\
\hline 1501 & & & & & $41 \%$ \\
\hline 2000 & 11 & & $17.77 \%$ & & $42 \%$ \\
\hline 2500 & & & $19.58 \%$ & & $44 \%$ \\
\hline 3000 & 13 & & & & $46 \%$ \\
\hline 4000 & 15 & & & & $48 \%$ \\
\hline 5000 & 17 & 4 & $31.40 \%$ & $80 \%$ & $53 \%$ \\
\hline 6000 & & & $35.24 \%$ & & $56 \%$ \\
\hline 7000 & 19 & & $39.09 \%$ & & \\
\hline 8000 & & & $42.93 \%$ & & $60 \%$ \\
\hline 9000 & 21 & & $46.77 \%$ & & \\
\hline 10000 & & 5 & $50.58 \%$ & $85 \%$ & $69 \%$ \\
\hline 12000 & 23 & & $54.71 \%$ & & \\
\hline 15000 & 25 & & & & $74 \%$ \\
\hline 20000 & 27 & 6 & $78.12 \%$ & $95 \%$ & $88 \%$ \\
\hline 25000 & 29 & & & & $94 \%$ \\
\hline 30000 & 31 & 7 & $107.39 \%$ & & \\
\hline 35000 & 33 & & & & $99 \%$ \\
\hline 40000 & 35 & & $136.65 \%$ & & \\
\hline 50000 & 37 & 8 & $168.67 \%$ & $105 \%$ & $116 \%$ \\
\hline 60000 & 39 & & & & \\
\hline 70000 & 41 & & & & \\
\hline 80000 & 43 & & $221.01 \%$ & $120 \%$ & $140 \%$ \\
\hline 90000 & 45 & & & & \\
\hline 100000 & 47 & 9 & & & \\
\hline 150000 & 49 & & & & $151 \%$ \\
\hline 200000 & 51 & 10 & & & \\
\hline 250000 & 53 & & & & \\
\hline 300000 & 55 & & & & \\
\hline
\end{tabular}

Note: The table represents the number of council members, alderman and the mayoral wage at different population levels. Boldface population thresholds witness a simultaneous increase in the wage of mayors and alderman as well as the number of council members at least during part of our time period (1977-2014), and are the focal point of the analysis in the main text. Note also that in the period 1977-2000, the mayoral wage increased in relatively small steps at no less than 152 thresholds between 2000 and 50000 inhabitants. To preserve space, we only included the main relevant increases in the table (full details upon request).

${ }^{a}$ Implemented by the Law of 4 May 1999; ${ }^{b}$ Implemented by the Decree of 15 July 2005. 
Table 2: Balance test between municipalities just below and above population thresholds

\begin{tabular}{l|cc|c}
\hline Variable & $\begin{array}{c}\text { Below threshold } \\
(N=938)\end{array}$ & $\begin{array}{c}\text { Above threshold } \\
(N=862)\end{array}$ & p-value \\
\hline Population size & 15256.85 & 14577.92 & 0.269 \\
Female (\%) & 50.811 & 50.727 & 0.169 \\
Elderly (\%) & 15.455 & 15.001 & 0.003 \\
Income (EUR) & 9.388 & 9.467 & 0.517 \\
Unemployment (\%) & 3.704 & 3.864 & 0.087 \\
Flanders (=1) & 0.515 & 0.500 & 0.527 \\
\hline
\end{tabular}

Note: The table includes only the sample of municipalities whose population size is within $2 \%$ of a population threshold associated with higher mayoral wages and council size. On the left-hand side are municipalities just below the population threshold, while on the right-hand side are municipalities just above the threshold. P-value refers to the statistical significance of a two-sided t-test assessing the difference between both subsamples. 
Table 3: Baseline regression results for municipal population developments

\begin{tabular}{l|cccc}
\hline Variable & Growth & Birth & Death & Net migration \\
& & & & \\
\hline Population threshold & $0.055 * *$ & -0.003 & $-0.009 *$ & $0.038 *$ \\
& $(0.023)$ & $(0.005)$ & $(0.005)$ & $(0.020)$ \\
Population size & $-0.000 * * *$ & $0.000 * * *$ & $-0.000 * * *$ & $-0.000 * *$ \\
& $(0.000)$ & $(0.000)$ & $(0.000)$ & $(0.000)$ \\
Income & $-0.051 * * *$ & $-0.003 *$ & $-0.003 *$ & $-0.063 * * *$ \\
& $(0.08)$ & $(0.002)$ & $(0.002)$ & $(0.007)$ \\
Unemployment & $0.053 * * *$ & $0.007 * *$ & $-0.007 * * *$ & -0.002 \\
& $(0.008)$ & $(0.003)$ & $(0.002)$ & $(0.007)$ \\
Elderly & $-0.083 * * *$ & $-0.022 * * *$ & $0.028 * * *$ & $-0.022 * * *$ \\
& $(0.004)$ & $(0.001)$ & $(0.009)$ & $(0.003)$ \\
Female & $0.231 * * *$ & 0.0004 & $0.014 * * *$ & 0.112 \\
& $(0.012)$ & $(0.004)$ & $(0.004)$ & $(0.011)$ \\
\hline Year FE & YES & YES & YES & YES \\
Municipality FE & YES & YES & YES & YES \\
\hline $\mathrm{N}$ & 18846 & 14725 & 14725 & 18846 \\
$\mathrm{R}^{2}$ (within) & 10.164 & 18.659 & 13.001 & 4.960 \\
\hline
\end{tabular}

Note: The respective dependent variables are the year-on-year population growth rate ('Growth'), the number of births as a share of the total population ('Birth'), the number of deaths as a share of the total population ('Death'), and the difference between the number of immigrants and emigrants as a share of the total population ('Net migration'). The central independent variable - 'Population threshold' - is an indicator variable equal to 1 for municipalities whose population size is within $2 \%$ of a population threshold associated with higher mayoral wages and council size (0 otherwise). All models include a full set of year and municipality fixed effects. Standard errors reported in brackets: $* * *$ significant at $1 \%$, ** at $5 \%$ and $*$ at $10 \%$. 
Table 4: Results for municipalities below or above threshold

\begin{tabular}{|c|c|c|c|c|}
\hline \multirow{2}{*}{ Variable } & Growth & Birth & Death & Net migration \\
\hline & \multicolumn{4}{|c|}{ Panel I: Below threshold } \\
\hline Population threshold & $\begin{array}{l}0.050 * \\
(0.030)\end{array}$ & $\begin{array}{l}-0.001 \\
(0.007)\end{array}$ & $\begin{array}{l}-0.008 \\
(0.006)\end{array}$ & $\begin{array}{c}0.022 \\
(0.027)\end{array}$ \\
\hline $\begin{array}{l}\text { Controls } \\
\text { Year FE } \\
\text { Municipality FE }\end{array}$ & $\begin{array}{l}\text { YES } \\
\text { YES } \\
\text { YES }\end{array}$ & $\begin{array}{l}\text { YES } \\
\text { YES } \\
\text { YES }\end{array}$ & $\begin{array}{l}\text { YES } \\
\text { YES } \\
\text { YES }\end{array}$ & $\begin{array}{l}\text { YES } \\
\text { YES } \\
\text { YES }\end{array}$ \\
\hline $\begin{array}{l}\mathrm{N} \\
\mathrm{R}^{2} \text { (within) }\end{array}$ & $\begin{array}{l}18846 \\
10.148\end{array}$ & $\begin{array}{l}14725 \\
18.654 \\
\end{array}$ & $\begin{array}{l}14725 \\
12.994 \\
\end{array}$ & $\begin{array}{l}18846 \\
4.950 \\
\end{array}$ \\
\hline & \multicolumn{4}{|c|}{ Panel II: Above threshold } \\
\hline Population threshold & $\begin{array}{l}0.059 * \\
(0.031)\end{array}$ & $\begin{array}{l}-0.004 \\
(0.007)\end{array}$ & $\begin{array}{l}-0.009 \\
(0.006)\end{array}$ & $\begin{array}{c}0.055 * * \\
(0.027)\end{array}$ \\
\hline Controls & YES & YES & YES & YES \\
\hline Year FE & YES & YES & YES & YES \\
\hline Municipality FE & YES & YES & YES & YES \\
\hline $\begin{array}{l}\mathrm{N} \\
\mathrm{R}^{2} \text { (within) }\end{array}$ & $\begin{array}{l}18846 \\
10.137\end{array}$ & $\begin{array}{l}14725 \\
18.651\end{array}$ & $\begin{array}{l}14725 \\
13.004\end{array}$ & $\begin{array}{l}18846 \\
4.930\end{array}$ \\
\hline
\end{tabular}

Note: The respective dependent variables are the year-on-year population growth rate ('Growth'), the number of births as a share of the total population ('Birth'), the number of deaths as a share of the total population ('Death'), and the difference between the number of immigrants and emigrants as a share of the total population ('Net migration'). The central independent variable - 'Population threshold' - is an indicator variable for municipalities whose population size is within $2 \%$ of a population threshold associated with higher mayoral wages and council size. In panel I, this indicator variable is 1 only for municipalities within a $2 \%$ range below a population threshold, while in panel II it is 1 only for municipalities within a $2 \%$ range above a population threshold. All models include controls for population size income, unemployment, age and gender distribution, as well as a full set of year and municipality fixed effects. Standard errors reported in brackets: *** significant at $1 \%$, ** at $5 \%$ and $*$ at $10 \%$. 
Table 5: Building permit results

\begin{tabular}{|c|c|c|c|c|c|}
\hline \multirow{2}{*}{ Variable } & $\begin{array}{c}\text { Residential } \\
\text { buildings }\end{array}$ & Apartments & $\begin{array}{l}\text { One-family } \\
\text { residences }\end{array}$ & $\begin{array}{c}\text { Non-residential } \\
\text { buildings }\end{array}$ & Renovations \\
\hline & \multicolumn{5}{|c|}{ Panel I: Below threshold } \\
\hline $\begin{array}{l}\text { Population threshold } \\
\text { (lagged) }\end{array}$ & $\begin{array}{l}8.519 * * * \\
(2.928)\end{array}$ & $\begin{array}{l}9.595 * * * \\
(2.579)\end{array}$ & $\begin{array}{l}-1.076 \\
(1.208)\end{array}$ & $\begin{array}{c}0.152 \\
(0.282)\end{array}$ & $\begin{array}{c}1.760 * * \\
(0.767)\end{array}$ \\
\hline $\begin{array}{l}\text { Controls } \\
\text { Year FE } \\
\text { Municipality FE }\end{array}$ & $\begin{array}{l}\text { YES } \\
\text { YES } \\
\text { YES }\end{array}$ & $\begin{array}{l}\text { YES } \\
\text { YES } \\
\text { YES }\end{array}$ & $\begin{array}{l}\text { YES } \\
\text { YES } \\
\text { YES }\end{array}$ & $\begin{array}{l}\text { YES } \\
\text { YES } \\
\text { YES }\end{array}$ & $\begin{array}{l}\text { YES } \\
\text { YES } \\
\text { YES }\end{array}$ \\
\hline \multirow[t]{2}{*}{$\mathrm{R}^{2}$ (within) } & $\begin{array}{l}9963 \\
5.459 \\
\end{array}$ & $\begin{array}{l}9963 \\
6.236 \\
\end{array}$ & $\begin{array}{l}9963 \\
8.608 \\
\end{array}$ & $\begin{array}{c}9963 \\
16.430 \\
\end{array}$ & $\begin{array}{c}9963 \\
11.110 \\
\end{array}$ \\
\hline & \multicolumn{5}{|c|}{ Panel II: Above threshold } \\
\hline $\begin{array}{l}\text { Population threshold } \\
\text { (lagged) }\end{array}$ & $\begin{array}{c}2.315 \\
(3.013) \\
\end{array}$ & $\begin{array}{l}1.272 \\
(2.655)\end{array}$ & $\begin{array}{c}1.043 \\
(1.243) \\
\end{array}$ & $\begin{array}{c}0.191 \\
(0.290) \\
\end{array}$ & $\begin{array}{l}1.522 * \\
(0.789)\end{array}$ \\
\hline Controls & YES & YES & YES & YES & YES \\
\hline Year FE & YES & YES & YES & YES & YES \\
\hline Municipality FE & YES & YES & YES & YES & YES \\
\hline $\begin{array}{l}\mathrm{N} \\
\mathrm{R}^{2} \text { (within) }\end{array}$ & 9963 & 9963 & 9963 & 9963 & 9963 \\
\hline $\mathrm{R}^{2}$ (within) & 5.383 & 6.117 & 8.606 & 16.430 & 11.138 \\
\hline
\end{tabular}

Note: The respective dependent variables are the absolute number of residential building permits ('Residential buildings'), permits for apartment buildings ('apartments'), permits for one-family residences ('One-family residence'), nonresidential building permits ('Non-residential buildings'), and permits for renovations of residential buildings ('Renovations'). The central independent variable - 'Population threshold' - is an indicator variable for municipalities whose population size is within $2 \%$ of a population threshold associated with higher mayoral wages and council size. In panel I, this indicator variable is 1 only for municipalities within a $2 \%$ range below a population threshold, while in panel II it is 1 only for municipalities within a $2 \%$ range above a population threshold. It is lagged by one period to accommodate the time lag between granting a permit, construction and moving into the residence. All models include controls for population size, income, unemployment, age and gender distribution, as well as a full set of year and municipality fixed effects. Standard errors reported in brackets: $* * *$ significant at $1 \%, * *$ at $5 \%$ and $*$ at $10 \%$. 


\section{Appendix A}

Table A.1: Summary statistics

\begin{tabular}{l|cccccc}
\hline Variable & Obs. & Mean & Std. Dev. & Min & Max & Time period \\
\hline Population threshold & 22382 & 0.082 & 0.274 & 0 & 1 & $1977-2014$ \\
& & & & & & \\
Population growth & 21792 & 0.513 & 0.909 & -9.576 & 13.146 & $1977-2013$ \\
Birth & 15312 & 1.123 & 0.214 & 0 & 3.798 & $1988-2013$ \\
Death & 15312 & 0.998 & 0.231 & 0 & 3.488 & $1988-2013$ \\
Net Migration & 19435 & 0.386 & 0.747 & -7.000 & 7.128 & $1981-2014$ \\
Residential buildings & 11090 & 81.445 & 109.324 & 0 & 1729 & $1996-2014$ \\
Apartments & 11090 & 39.929 & 85.494 & 0 & 1598 & $1996-2014$ \\
One-family residence & 11090 & 41.516 & 39.081 & 0 & 811 & $1996-2014$ \\
Non-residential buildings & 11090 & 8.661 & 9.862 & 0 & 140 & $1996-2014$ \\
Renovations & 11090 & 44.228 & 56.649 & 0 & 1008 & $1996-2014$ \\
& & & & & & $1996-2014$ \\
Controls & & & & & & \\
Population size & 22382 & 17368.6 & 28811.94 & 80 & 530826 & $1977-2014$ \\
Income & 21204 & 9.678 & 2.525 & 3.424 & 19.405 & $1977-2012$ \\
Unemployment & 20596 & 3.587 & 1.793 & 0 & 15.831 & $1980-2014$ \\
Elderly & 20026 & 15.656 & 2.874 & 5.020 & 33.880 & $1981-2014$ \\
Female & 20024 & 50.745 & 1.067 & 43.529 & 57.738 & $1981-2014$ \\
Flanders & 22382 & 0.523 & 0.499 & 0 & 1 & $1977-2014$ \\
\hline
\end{tabular}

Note: Population threshold is an indicator variable equal to 1 for municipalities whose population size is within $2 \%$ of a population threshold associated with higher mayoral wages and council size ( 0 otherwise). Population growth is the year-on-year change in the municipality's population size (in percent). Birth and Death are the number of births (deaths) as a share of the total population. Net Migration is the difference between the number of immigrants and emigrants as a share of the total population. Residential buildings (Apartments, One-family residence, Nonresidential buildings, Renovations) is the absolute number of building permits for residential properties (residential apartments, for one-family residences, for non-residential properties, renovations of residential buildings). Income is the average real per capita income in the municipality (in 1000EUR, base year is 2000). Unemployment, elderly and female are expressed as a share of the total municipal population. Flanders is an indicator variable equal to 1 for municipalities in Flanders (0 for municipalities in Brussels and Wallonia). 


\section{ONLINE APPENDIX}

Table X.1: Placebo tests using alternative arbitrary population thresholds

\begin{tabular}{|c|c|c|c|c|}
\hline \multirow[t]{2}{*}{ Variable } & \multicolumn{4}{|c|}{ Panel I: Population developments } \\
\hline & Growth & Birth & Death & Net migration \\
\hline Population threshold & $\begin{array}{l}-0.004 \\
(0.030)\end{array}$ & $\begin{array}{c}0.005 \\
(0.007)\end{array}$ & $\begin{array}{c}0.003 \\
(0.006)\end{array}$ & $\begin{array}{l}-0.002 \\
(0.027)\end{array}$ \\
\hline Controls & YES & YES & YES & YES \\
\hline Year FE & YES & YES & YES & YES \\
\hline Municipality FE & YES & YES & YES & YES \\
\hline $\mathrm{N}$ & 18846 & 14725 & 14725 & 18846 \\
\hline \multirow[t]{3}{*}{$\mathrm{R}^{2}$ (within) } & 10.130 & 18.650 & 13.000 & 4.920 \\
\hline & \multicolumn{4}{|c|}{ Panel II: Housing policy } \\
\hline & Apartments & $\begin{array}{c}\text { One-family } \\
\text { residences }\end{array}$ & $\begin{array}{c}\text { Non-residential } \\
\text { buildings }\end{array}$ & Renovations \\
\hline Population threshold & $\begin{array}{l}-1.036 \\
(2.410)\end{array}$ & $\begin{array}{c}-1.068 \\
(1.127)\end{array}$ & $\begin{array}{l}-0.167 \\
(0.263)\end{array}$ & $\begin{array}{c}0.220 \\
(0.716)\end{array}$ \\
\hline Controls & YES & YES & YES & YES \\
\hline Year FE & YES & YES & YES & YES \\
\hline Municipality FE & YES & YES & YES & YES \\
\hline $\mathrm{N}$ & 9963 & 9963 & 9963 & 9963 \\
\hline $\mathrm{R}^{2}$ (within) & 6.100 & 8.610 & 16.430 & 11.060 \\
\hline
\end{tabular}

Note: In Panel I, the respective dependent variables are the year-on-year population growth rate ('Growth'), the number of births as a share of the total population ('Birth'), the number of deaths as a share of the total population ('Death'), and the difference between the number of immigrants and emigrants as a share of the total population ('Net migration'). In panel II, the dependent variables are the absolute number of residential building permits ('Residential buildings'), permits for apartment buildings ('apartments'), permits for onefamily residences ('One-family residence'), non-residential building permits ('Non-residential buildings'), and permits for renovations of residential buildings ('Renovations'). The central independent variable - 'Population threshold' - is an indicator variable for municipalities whose population size is within $2 \%$ of a placebo population threshold (details in main text). In all models, we set this indicator variable equal to 1 for municipalities within a $2 \%$ range below the placebo threshold. All models include controls for population size, income, unemployment, age and gender distribution, as well as a full set of year and municipality fixed effects. Standard errors reported in brackets: *** significant at $1 \%, * *$ at $5 \%$ and $*$ at $10 \%$. 
Table X.2: Placebo tests on building permits using forward lag

\begin{tabular}{l|ccccc}
\hline Variable & $\begin{array}{c}\text { Residential } \\
\text { buildings }\end{array}$ & Apartments & $\begin{array}{c}\text { One-family } \\
\text { residences }\end{array}$ & $\begin{array}{c}\text { Non-residential } \\
\text { buildings }\end{array}$ & Renovations \\
\hline Population threshold & -2.672 & -0.488 & $-2.184 *$ & $-0.489 *$ & 0.753 \\
(forward lag) & $(2.947)$ & $(2.597)$ & $(1.215)$ & $(0.283)$ & $(0.772)$ \\
\hline Controls & YES & YES & YES & YES & YES \\
Year FE & YES & YES & YES & YES & YES \\
Municipality FE & YES & YES & YES & YES & YES \\
\hline $\mathrm{N}$ & 9963 & 9963 & 9963 & 9963 & 9963 \\
$\mathrm{R}^{2}$ (within) & 5.375 & 6.104 & 8.613 & 16.440 & 11.058 \\
\hline
\end{tabular}

Note: The respective dependent variables are the absolute number of residential building permits ('Residential buildings'), permits for apartment buildings ('apartments'), permits for one-family residences ('One-family residence'), nonresidential building permits ('Non-residential buildings'), and permits for renovations of residential buildings ('Renovations'). The central independent variable - 'Population threshold' - is an indicator variable for municipalities whose population size is within $2 \%$ of a placebo population threshold (details in main text). In all models, we set this indicator variable equal to 1 for municipalities within a $2 \%$ range below the placebo threshold. It is forwarded by one period as a placebo test. All models include controls for population size, income, unemployment, age and gender distribution, as well as a full set of year and municipality fixed effects. Standard errors reported in brackets: *** significant at $1 \%, * *$ at $5 \%$ and $*$ at $10 \%$. 